\title{
THEORETICAL STUDY AND ANALYSIS OF O- NITROPHENOL ADSORPTION USING LAYERED DOUBLE HYDROXIDES CONTAINING CA-AL, NI-AL AND ZN-AL
}

Lotfi Sellaoui, Amira Yazidi, Jawad Ali, Guilherme Luiz Dotto, Adrian BonillaPetriciolet, Luis F. S. Oliveira, Michael Badawi, Zhuqi Chen

\begin{abstract}
A theoretical assessment of the o-nitrophenol adsorption on layered double hydroxides containing different metallic species (Ca-Al, Ni-Al and $\mathrm{Zn}-\mathrm{Al}$ ) was performed. Experimental o-nitrophenol adsorption isotherms obtained at different adsorption temperatures with these layered double hydroxides were analyzed using a statistical physics monolayer model. Model calculations showed that the onitrophenol aggregation could occur with a high degree. It was estimated that the onitrophenol adsorption implied a non-flat orientation on all adsorbent surfaces and this process was multi-molecular. It was also demonstrated that there was no significant difference on the o-nitrophenol adsorption capacities of tested adsorbents, which varied from 77 to 135,95 to 122 and 74 and $130 \mathrm{mg} / \mathrm{g}$ for Ca-Al, $\mathrm{Ni}-\mathrm{Al}$ and $\mathrm{Zn}$-Al layered double hydroxides, respectively. This finding suggested that the incorporation of $\mathrm{Ca}-\mathrm{Al}, \mathrm{Ni}-\mathrm{Al}$ and $\mathrm{Zn}-\mathrm{Al}$ in the layered double hydroxide structure played a similar role to adsorb o-nitrophenol molecules from aqueous solution. Calculated adsorption energies and thermodynamic functions confirmed an exothermic adsorption with the presence of physical-based interaction forces. This paper highlights the importance of reliable theoretical calculations based on statistical physics theory to contribute in the understanding of the adsorption mechanisms of a relevant water pollutant using layered double hydroxides as promising adsorbents for industrial applications.
\end{abstract}

\section{Keywords}

Layered double hydroxides; Modelling; Multi-molecular adsorption; O-nitrophenol 